\title{
Diagnostic cholangioscopy with SpyGlass probe through an endoscopic retrograde cholangiopancreatography cannula
}

We report on a technique for performing cholangioscopy using the reusable 0.77-mm SpyGlass fiberoptic probe (Boston Scientific, Massachusetts, USA) with two double-lumen endoscopic retrograde cholangiopancreatography (ERCP) cannulae. The Tandem XL cannula (Boston Scientific) is a 7-Fr double-lumen catheter with a 5.5-Fr tip ( $\bullet$ Fig. 1 a), and the Swing-tip cannula (Olympus, Tokyo, Japan) is a 9-Fr single-lumen catheter with a 4.5-Fr tip with bi-directional swing angle of $105^{\circ}$ ( Fig. 1b) and is used when SpyGlass cholangioscopy is less than ideal (i.e. no sphincterotomy, small-caliber duct) [1,2]. Cholangioscopy using the SpyGlass probe and Tandem catheter (without sphincterotomy) was used to clarify the nature of the round filling defects in the left intrahepatic ducts in a patient with jaundice and a history of right hepatectomy for metastatic colon cancer. In contrast to the suspected biliary stones, a polypoid tumor was found, consistent with recurrent disease ( $\bullet$ Fig. 2 a, b).

In the second patient, combined SpyGlass probe and Swing-tip cannula (irrigation via Touhy Borst attachment) was used to determine whether complete clearance of stone fragments had been achieved following mechanical lithotripsy of a large common bile duct stone ( $\bullet$ Fig. 2 c, d).

The major advantage of this technique is the ability to cannulate non-dilated or small biliary (or pancreatic) ducts without the need for sphincterotomy, which would be useful for patients who are at risk for sphincterotomy complications due to bleeding diathesis or who have unfavorable anatomy (e.g. small ampulla, Billroth II gastrectomy). It would also be useful for examining lesions located in the small intrahepatic ducts, which would be difficult for the 3.3-mm caliber SpyScope to reach $[1,2]$. Furthermore, this technique is extremely cost-effective for selected diagnostic cases. The cost of the Tandem XL catheter is one-tenth (US\$ 67) and the Swing-tip cannula one-fifth (US\$130) of the SpyScope assembly (US\$670). With the lifespan of up to 20 uses [2], the estimated cost of the SpyProbe per use is US\$250.
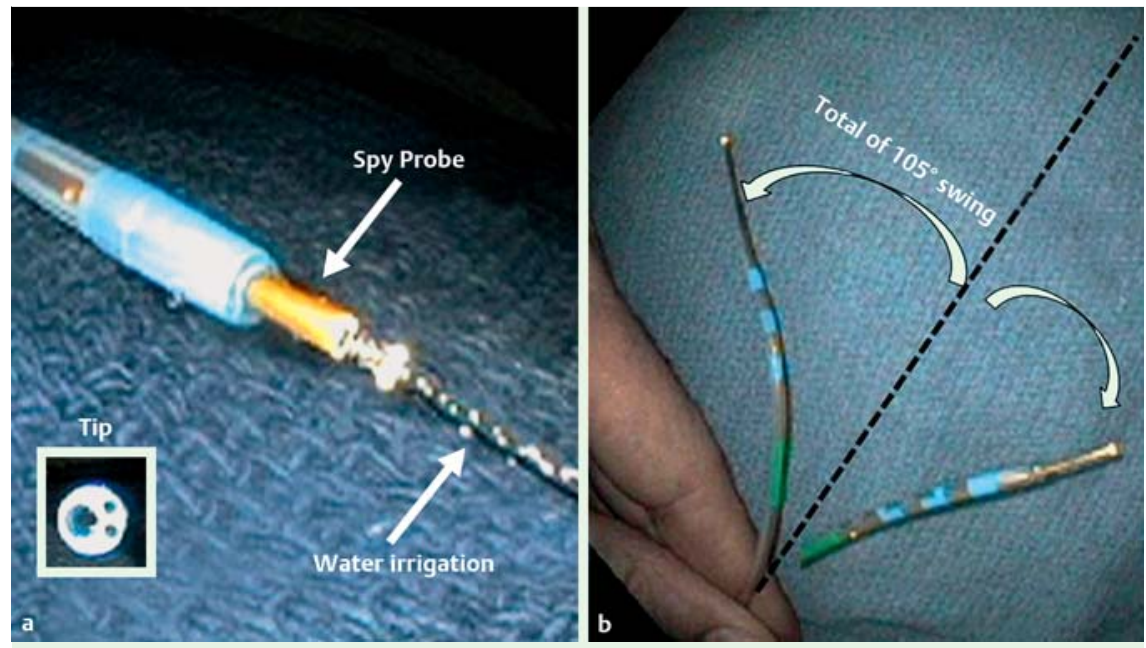

Fig. 1 Cannulae used with the SpyGlass probe. Tandem XL cannula (a) and Swing-tip cannula (b) with in situ SpyGlass probe. These cannulae can accommodate both the SpyGlass optical probe and water irrigation. The Swing-tip cannula has a maximum bi-directional angulation of $105^{\circ}$.
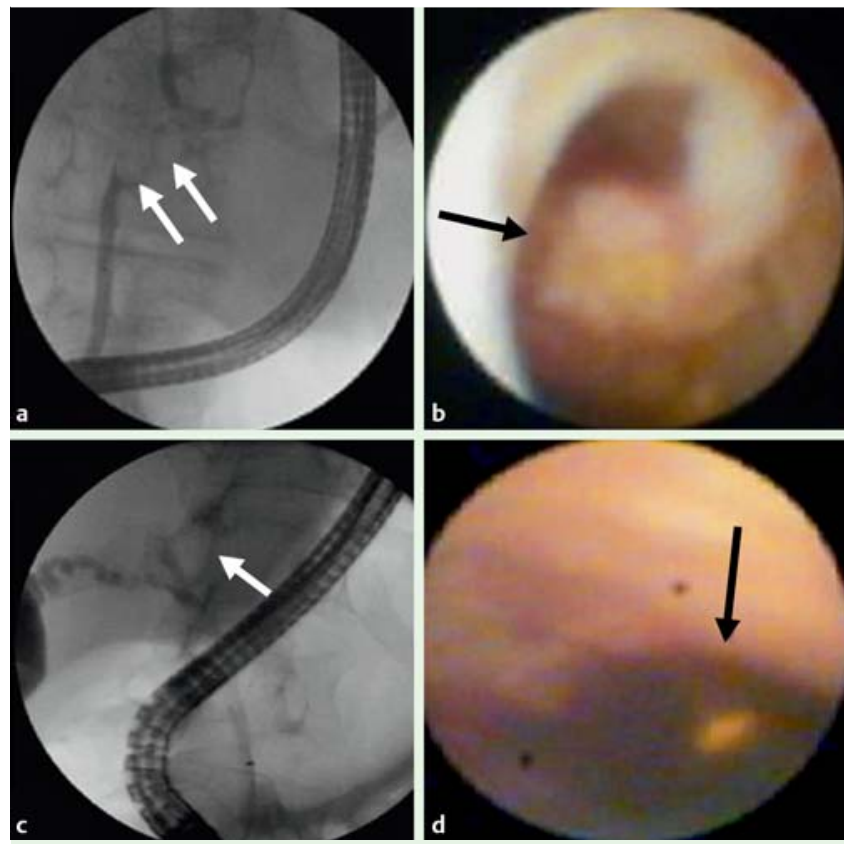

Fig. 2 Patient images following cholangioscopy with SpyGlass probe and double-lumen endoscopic retrograde cholangiopancreatography (ERCP) cannulae. a Patient 1, a jaundiced patient was suspected of having left intrahepatic ductal stones (double arrow) following routine cholangiography, and $\mathbf{b}$ underwent cholangioscopy using the SpyGlass probe and the Tandem catheter, which showed a polypoid cholangiocarcinoma (thick arrow). c Patient 2 underwent successful mechanical lithotripsy to remove a large bile duct stone (thin arrow). $\mathbf{d}$ The SpyGlass through cannula technique was used to verify stone clearance. Cholangioscopy revealed a large residual stone fragment (thick arrow). 
Endoscopy_UCTN_Code_TTT_1AR_2AB

N. Q. Nguyen ${ }^{1,2}$, J. N. Shah ${ }^{1}$, K. F. Binmoeller ${ }^{1}$

1 Interventional Endoscopy Services, California Pacific Medical Center,

San Francisco, USA

2 Department of Gastroenterology and Hepatology, Royal Adelaide Hospital, Adelaide, South Australia

\section{References}

1 Chen YK, Pleskow DK. SpyGlass single-operator peroral cholangiopancreatoscopy system for the diagnosis and therapy of bileduct disorders: a clinical feasibility study (with video). Gastrointest Endosc 2007; 65: $832-841$

2 Chen YK. Preclinical characterization of the Spyglass peroral cholangiopancreatoscopy system for direct access, visualization, and biopsy. Gastrointest Endosc 2007; 65: 303 311

\section{Bibliography}

DOI $10.1055 / \mathrm{s}-0030-1255707$

Endoscopy 2010; 42: E288 -E289

(c) Georg Thieme Verlag KG Stuttgart · New York . ISSN 0013-726X

\section{Corresponding author}

\section{K. F. Binmoeller, MD}

Interventional Endoscopy Services California Pacific Medical Center

2351 Clay St. \#600

San Francisco

California 94115

USA

Fax: +1-415-600-1416

BinmoeK@sutterhealth.org 